\title{
Evolving use of embolisation coils for occlusion of the arterial duct
}

\author{
Eric Rosenthal, Shakeel A Qureshi, John Reidy, Edward J Baker, Michael Tynan
}

\begin{abstract}
Objective-To assess the outcome of arterial duct occlusion with coils chosen according to the duct morphology.

Design-Retrospective study.

Setting-Paediatric cardiology centre.

Patients-Coil occlusion was attempted in 57 patients aged 0.5 to 15 (median $3 \cdot 7$ ) years and weighing 5-59 (median 14) kg between January 1991 and December 1995. A residual leak was present in 8 patients after umbrella closure and in 4 patients after duct ligation.
\end{abstract}

Methods-Coils of 4 different types were implanted through 4 or $5 \mathrm{~F}$ femoral artery catheters. Platinum or Interlocking Detachable 0.018 inch coils were deployed completely inside tubular ducts. Gianturco or PDA controlled release 0.038 inch coils were implanted to straddle short, post ligation and post umbrella ducts.

Results-Coil implantation was successful in 54/57 patients. At 1 year the cumulative occlusion rate was $53 / 57$ ducts $(93 \%)$ on an intention to treat analysis. A single coil was implanted in $37(69 \%), 2$ coils in $10(19 \%), 3$ coils in $3(5 \%)$ and 4 coils in 4 (7\%) of the 54 successful procedures. Duct occlusion was documented at the end of the procedure in $31 \%$, by the following day in $83 \%$, by 6 weeks in $87 \%$, by 6 months in $96 \%$, and by 1 year in $98 \%$. Coil embolisation occurred in $6 / 58$ procedures $(10 \%)$, with a $50 \%$ rate in the first year of implantation (1/2 patients) falling to $7 \%$ in the last year (3/42 patients). All embolised coils were easily retrieved.

Conclusions-Occlusion of small to moderate size arterial ducts, including residual post umbrella or post ligation ducts, was readily accomplished by coils selected according to the duct anatomy. This has both cost and practical benefits.

(Heart 1996;76:525-530)

Keywords: arterial duct occlusion; coil occlusion

Transcatheter occlusion of the arterial duct using Rashkind umbrellas is now standard practice in most European paediatric cardiol- ogy centres. ${ }^{1}$ Deployment into small arterial ducts, however, can be difficult and strategies such as balloon or serial catheter dilatation of the duct or creation of an arteriovenous guidewire circuit are often required. ${ }^{2}$ These add to the complexity of the procedure. A residual leak is present in up to $10-20 \%$ of ducts though the incidence falls with time. ${ }^{3}$ Implantation of a second device is possible, ${ }^{4}$ though if the residual leak is small, this may also be difficult. In small infants implantation of a Rashkind device may not be possible because of the size of the delivery system and the device itself. ${ }^{56}$

In the USA, where the Rashkind device originated, its use has been restricted because of regulatory issues. More recently, Gianturco coils have been used as an alternative transcatheter approach. Several series have demonstrated their effectiveness for occluding small to moderate sized ducts with single or multiple coils during the same procedure. ${ }^{7-9}$

In our centre, coils were first implanted into the arterial duct in 1991. The technique and its evolution is described in this study.

\section{Patients and methods}

PATIENTS

Coil implantation was attempted in 57 patients aged 0.5 to 15 years (median 3.7 years) and weighing 5 to $59 \mathrm{~kg}$ (median $14 \mathrm{~kg}$ ) between January 1991 and December 1995. Duct ligation had been performed previously in four patients, and in two of these a subsequent Rashkind umbrella implantation had failed. A Rashkind umbrella had been implanted in eight patients $(12 \mathrm{~mm}$ device in two patients and $17 \mathrm{~mm}$ device in six patients) 2-17 months previously. In one patient implantation of a Rashkind umbrella had failed.

Associated conditions included an atrial septal defect in two patients (one with Goldenhar's syndrome and one with Down's syndrome), a ventricular septal defect in three patients (one restrictive and two closed surgically), coarctation or recoarctation of the aorta in three patients, aortic stenosis in two patients, and repaired Tetralogy of Fallot in one patient. Two children had a Marfan-like connective tissue disorder and three had congenital complete heart block. Two children 
had Down's syndrome, one child had undergone a Kasai operation, and one had propionic acidaemia.

COILS

Coils of four different types were used.

Platinum fibre 0.018 inch coils (William Cook Europe, Denmark or Target Therapeutics, USA), $2-3 \mathrm{~mm}$ in diameter by $1-3 \mathrm{~cm}$ in length were deployed using a 0.018 inch guidewire.

Interlocking Detachable 0.018 inch platinum coils (Target Therapeutics), 2-6 $\mathrm{mm}$ in diameter by $1-20 \mathrm{~cm}$ in length, were advanced with an interlocking detachable pushing wire and were retrievable up until the point of release.

Gianturco 0.038 inch stainless steel fibre coils (William Cook Europe), $3 \mathrm{~mm}$ in diameter and $4 \mathrm{~cm}$ in length $(8 \mathrm{~mm}$ by $2 \mathrm{~cm}$ in one patient), were deployed using a 0.035 inch guidewire.

PDA 0.038 inch stainless steel fibre coils (William Cook Europe), 3-8 $\mathrm{mm}$ in diameter by $4-12 \mathrm{~cm}$ in length were attached by a screw mechanism to a pushing wire and were retrievable up until the point of release.

\section{COIL IMPLANTATION}

Coil implantation was performed with the patient sedated or under general anaesthesia. Initially a 6 or $7 \mathrm{~F}$ catheter was placed through a femoral vein into the pulmonary artery to serve as a guide and for sizing of the duct. A 5 $\mathrm{F}$ pigtail or NIH catheter advanced through a femoral artery sheath was used for angiography to delineate the size, shape, and position of the duct. Latterly, the venous catheter was omitted and a $4 \mathrm{~F}$ sheath was used in a femoral artery. A 4 or $5 \mathrm{~F}$ multipurpose or cobra catheter with an 0.038 inch lumen was advanced either into or across the duct from the same arterial sheath. For 0.018 inch coils a Tracker 18 catheter (Target Therapeutics) introduced through the 4 or $5 \mathrm{~F}$ catheter was used to implant the coils entirely within the duct. The 0.038 inch coils were deployed by extruding 1-2 loops through the 4 or $5 \mathrm{~F}$ catheter into the pulmonary artery, withdrawing the extruded loops to the pulmonary artery orifice of the duct, and then withdrawing the catheter to deposit the remaining loops inside the duct and in the aortic ampulla. Additional coils were implanted if a significant leak remained.

At the end of the procedure a final aortogram was performed. Flucloxacillin and gen- tamicin were administered during the procedure and for the next 24 hours. The patients were discharged the following day after a colour flow Doppler study. Doppler studies were repeated at six weeks, six months, and one year.

CHOICE OF COIL

Coil implantation was initially attempted when the size and shape of the duct posed difficulties for simple implantation of a Rashkind umbrella. In addition, the duct shape was such that it was thought possible to implant the coil completely within the duct and avoid coil loops projecting into either the aorta or pulmonary artery. Thus in the early part of the series 0.018 inch platinum fibre coils were the most commonly used because the alternative was the stiffer Gianturco coils which were less suited to implantation inside the duct.

Subsequently, after evidence that implantation of coils with loops protruding into the aorta and pulmonary artery was safe, ${ }^{7-9}$ coil implantation was extended to ducts that could have been closed by implantation of a Rashkind umbrella. Initially only smaller ducts (narrowest diameter less than $2 \mathrm{~mm}$ ) were attempted with coil diameters of at least twice the minimum diameter. With experience, larger ducts, in which more than one coil was required, were selected. Residual leaks after implantation of a Rashkind occluder also became eligible for this technique. The Gianturco coil was the initial coil of choice until the similar PDA coil, with its safety release mechanism, became available. For ducts where it was possible to implant the coils wholly inside the duct, the Interlocking Detachable Coil became the preferred coil.

Table 1 shows the types of coil by year of implantation together with the concomitant decline in umbrella use.

\section{ETHICAL CONSIDERATIONS}

In the first cohort the occlusion procedure was identical to that used for embolising collateral arteries and other vessels ${ }^{10}$ and was potentially simpler than Rashkind umbrella implantation and was indicated clinically. In the second era the straddling coil technique had already become established and reported ${ }^{7-9}$ and ethical permission was therefore unnecessary.

\section{Results}

Implantation was successful in 54 of the 57 patients. In one patient the coil embolised and

Table 1 Type of coil by year of implantation

\begin{tabular}{|c|c|c|c|c|c|c|c|}
\hline \multirow[b]{2}{*}{ Year } & \multirow{2}{*}{$\begin{array}{l}\text { Number of } \\
\text { procedures } \\
\left.\text { (total } 58^{\star}\right)\end{array}$} & \multicolumn{4}{|c|}{ Type of coil } & \multirow{2}{*}{$\begin{array}{l}\text { Coil } \\
\text { embolisation } \\
\text { (number (\%)) }\end{array}$} & \multirow{2}{*}{$\begin{array}{l}\text { Rashkind } \\
\text { umbrella } \\
\text { implants }\end{array}$} \\
\hline & & $\begin{array}{l}\text { Platinum } \\
\text { fibre }\end{array}$ & Gianturco & $\begin{array}{l}\text { Interlocking } \\
\text { Detachable }\end{array}$ & $P D A$ & & \\
\hline 1991 & 2 & 1 & $1^{\star}$ & & & $1(50 \%)$ & 38 \\
\hline 1992 & 3 & 3 & & & & $1(33 \%)$ & 35 \\
\hline 1993 & - & & & & & & 46 \\
\hline 1994 & 11 & & 5 & 3 & 3 & $1(9 \%)$ & 44 \\
\hline 1995 & 42 & & 18 & 4 & 20 & $3(7 \%)$ & 5 \\
\hline
\end{tabular}

Rashkind umbrella implantation is given to show the change in practice of duct occlusion.

* One patient underwent two procedures. The first in 1991 resulted in embolisation of the Gianturco coil but coil implantation was successful at the second procedure in 1992 when platinum fibre coils were used.

tAll embolised coils were retrieved by means of a transcatheter approach. 
Table 2 Time course of arterial duct occlusion after successful coil implantation according to coil type *

\begin{tabular}{|c|c|c|c|c|c|c|c|c|}
\hline \multirow[b]{2}{*}{ Coil type } & \multirow[b]{2}{*}{ No } & \multicolumn{6}{|c|}{ Time of occlusion } & \multirow{2}{*}{$\begin{array}{l}\text { Occlusion } \\
\text { rate } \\
(\%)\end{array}$} \\
\hline & & $\begin{array}{l}\text { At } \\
\text { catheter }\end{array}$ & $\begin{array}{l}1 \\
d a y\end{array}$ & $\begin{array}{l}6 \\
\text { weeks }\end{array}$ & $\begin{array}{l}6 \\
\text { months }\end{array}$ & $\begin{array}{l}1 \\
\text { year }\end{array}$ & $\begin{array}{l}\text { Not } \\
\text { occluded }\end{array}$ & \\
\hline $\begin{array}{l}\text { Platinum fibre } \\
\text { IDC } \\
\text { Gianturco } \\
\text { PDA }\end{array}$ & $\begin{array}{r}3 \\
7 \\
22 \\
22\end{array}$ & $\begin{array}{r}1 \\
10 \\
6\end{array}$ & $\begin{array}{r}1 \\
2 \\
11 \\
14\end{array}$ & $\begin{array}{l}1 \\
1\end{array}$ & $\begin{array}{l}1 \\
3 \\
1\end{array}$ & 1 & 1 & $\begin{array}{r}100 \\
100 \\
100 \\
95\end{array}$ \\
\hline
\end{tabular}

${ }^{\star}$ Excludes three patients in whom coil implantation was not successful.

Table 3 Time course of arterial duct occlusion after successful coil implantation according to duct type and coil position *

\begin{tabular}{|c|c|c|c|c|c|c|c|c|}
\hline \multirow[b]{2}{*}{ Duct } & \multirow[b]{2}{*}{ No } & \multicolumn{6}{|c|}{ Time of occlusion } & \multirow{2}{*}{$\begin{array}{l}\text { Occlusion } \\
\text { rate } \\
(\%)\end{array}$} \\
\hline & & $\begin{array}{l}\text { At } \\
\text { catheter }\end{array}$ & $\begin{array}{l}1 \\
\text { day }\end{array}$ & $\begin{array}{l}6 \\
\text { weeks }\end{array}$ & $\begin{array}{l}6 \\
\text { months }\end{array}$ & $\begin{array}{l}1 \\
\text { year }\end{array}$ & $\begin{array}{l}\text { Not } \\
\text { occluded }\end{array}$ & \\
\hline Native duct: & 43 & 14 & 23 & 2 & 3 & & & 100 \\
\hline Coil inside & 9 & 1 & 3 & 1 & 3 & 1 & & 100 \\
\hline Coil straddle & 34 & 13 & 20 & 1 & & & & 100 \\
\hline Post ligation & 4 & 2 & 2 & & & & & 100 \\
\hline Post umbrella & 7 & $\overline{1}$ & 3 & & 2 & & 1 & 86 \\
\hline
\end{tabular}

ॠExcludes three patients in whom coil implantation was not successful.

was not replaced. In two patients the coil was deployed but removed because of complications (see later). One coil was implanted in 37 $(69 \%)$, two coils in $10(19 \%)$, three coils in three $(5 \%)$, and four coils in four $(7 \%)$. In the last 17 patients $4 \mathrm{~F}$ sheaths and catheters were used in the femoral artery. There were no arterial complications. The time course of duct occlusion is shown in tables 2 and 3 . The cumulative occlusion rate was $93 \%(53 / 57)$ at one year on an intention to treat analysis and $98 \%(53 / 54)$ for successful implantations.
1991-1992

Coil implantation into long tubular ducts was successful in three of four patients with 0.018 inch platinum fibre coils (1-3 coils per patient) with complete occlusion (table 2 ). In one patient an inappropriately large diameter Gianturco coil placed inside the duct embolised and was retrieved from the descending aorta with a basket snare. Coil occlusion with smaller platinum fibre coils was successful at a second procedure. In a patient with coarctation of the aorta, a platinum fibre
Figure 1 A long tubular duct (a) has a $15 \mathrm{~cm} \times$ $5 \mathrm{~mm}$ Interlocking

Detachable Coil implanted (b) leaving a small jet leak (c). After implantation of a second $8 \mathrm{~cm} \times 4 \mathrm{~mm}$ Interlocking Detachable Coil (d) there is virtual occlusion (e) and no leak on Doppler examination the next day.

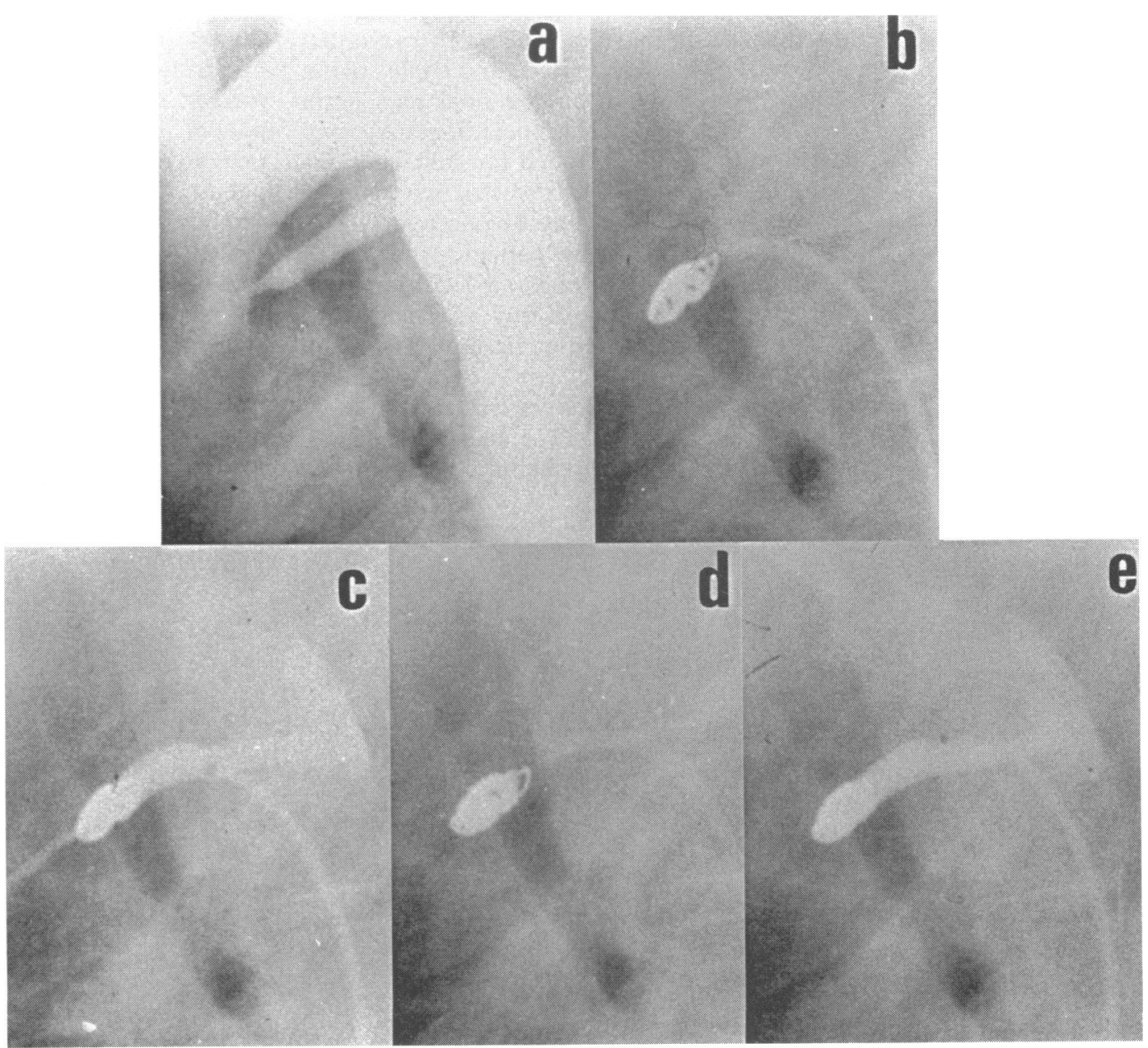


Figure 2 single $4 \mathrm{~cm}$ $\times 3 \mathrm{~mm}$ coil is implanted into a small native duct (a) but has most of its turns in the pulmonary artery (b). After elective removal with a snare (c) two further similar coils are implanted more accurately, resulting in complete occlusion.

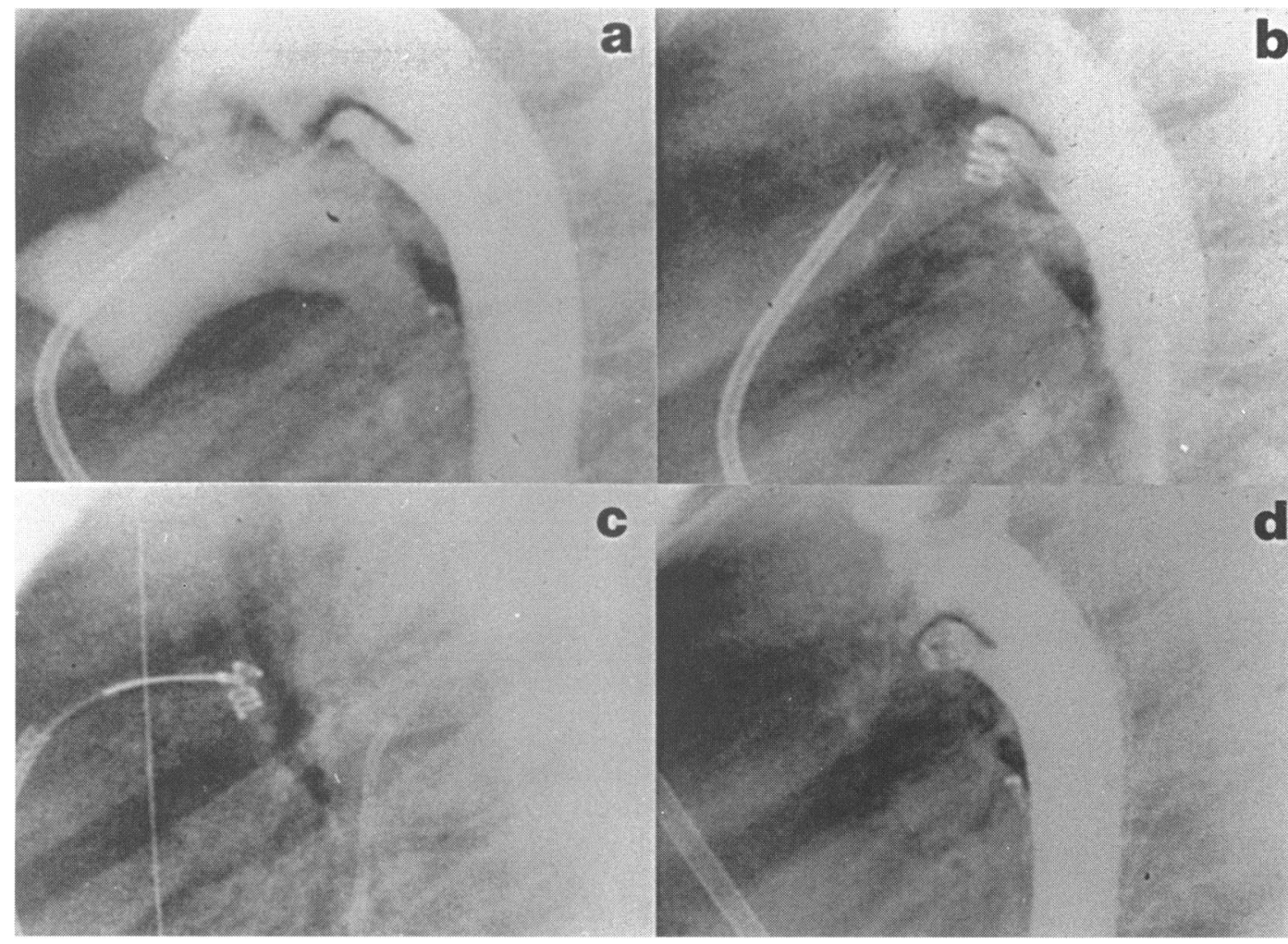

coil embolised to the popliteal artery and was retrieved with a snare. After balloon dilatation of the coarctation was unsuccessful, he underwent surgical ligation and coarctation repair.

\section{4-1995}

Interlocking Detachable Coils were placed inside the duct in six patients (one or two coils per patient). None embolised and only trivial shunts were present on the final angiogram (fig 1). On Doppler echocardiography two (29\%) ducts were occluded the following day (table 2), one more by six weeks, two more by six months, and one more by one year $(100 \%$ occlusion rate). In one patient, who had a Rashkind umbrella in place, a $1 \mathrm{~cm}$ long coil was placed to straddle a tiny residual shunt. The duct was occluded at six months (no six week study).

Gianturco or PDA coils were used to straddle the duct in 46 patients ( $1-4$ coils per patient). In one patient with a Rashkind umbrella and a mild recoarctation the coil increased the gradient and was removed and the procedure abandoned. Haemolysis developed in one patient with a single PDA coil $(8 \mathrm{~mm})$ and a significant residual shunt. The coil was removed 48 hours later and replaced with a Rashkind umbrella. In the remaining 44 patients the duct was occluded on the final angiogram in $16(36 \%)$ patients, by the following day in a further $25(57 \%)$ patients, by six weeks in one patient $(2 \%)$, by six months in one $(2 \%)$ patient but was still patent at one year in a patient with a Rashkind umbrella in place (table 2). There were four embolisations (two Gianturco and two PDA) managed by transcatheter retrieval and re-implantation of a similar or larger coil. In two patients a Gianturco coil was implanted with nearly all the loops either on the pulmonary artery side or the aortic side of the duct. These were electively retrieved and replaced with similar coils more accurately (fig 2).

b

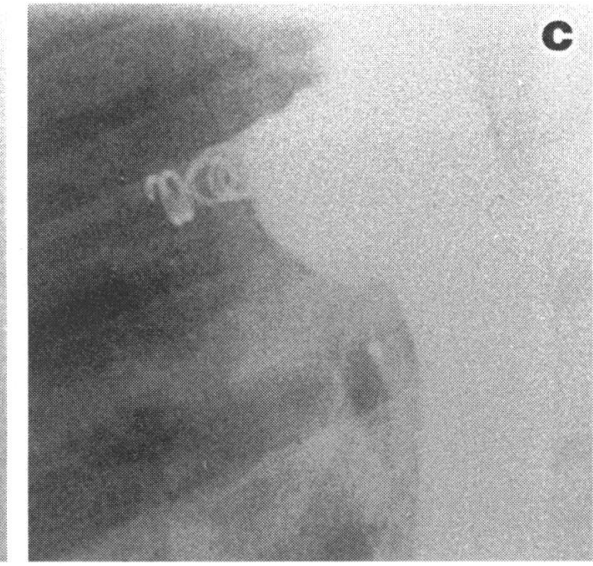

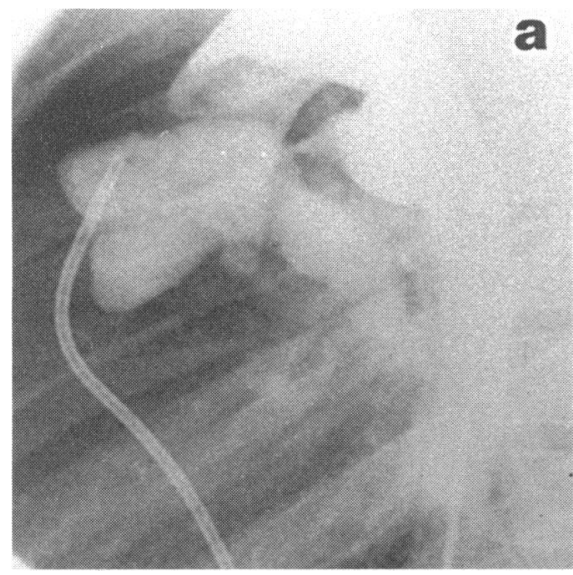

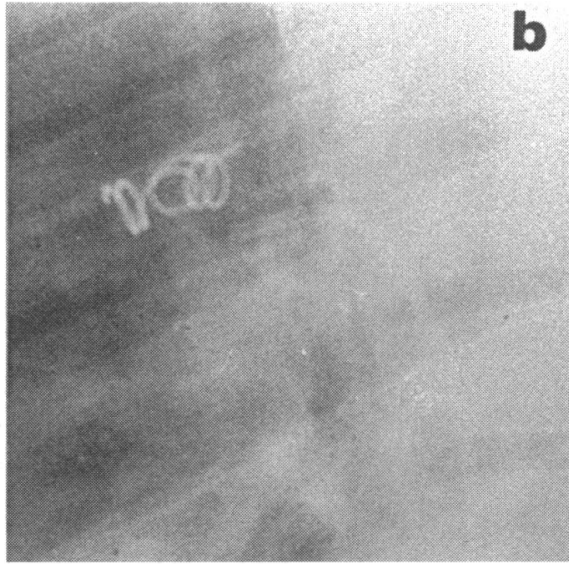

Figure 3 A residual duct after duct ligation (a) has a single $8 \mathrm{~cm} \times 5 \mathrm{~mm} P D A$ coil implanted (b) resulting in immediate complete occlusion (c). 
Figure 4 A small leak after implantation of a $17 \mathrm{~mm}$ Rashkind umbrella one year previously (a) $A$ single $8 \mathrm{~cm} \times 5 \mathrm{~mm}$ $P D A$ coil is implanted (b) resulting in complete occlusion (c).
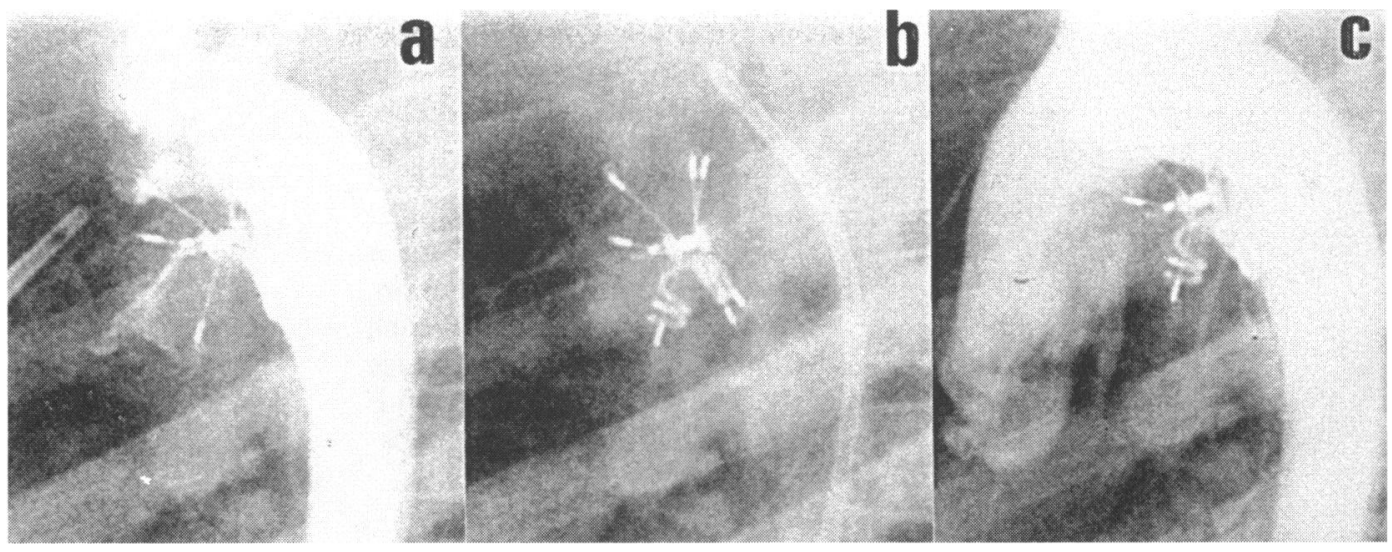

Post duct ligation-In four patients the duct was occluded with one or two Gianturco or PDA coils (fig 3); at the end of the procedure in two $(50 \%)$ and by the following day in the other two (50\%) patients (table 3).

Previous Rashkind umbrella procedure-Coil implantation was successful in seven of eight patients. In one patient with a mild recoarctation the Gianturco coil increased the gradient in the aorta and was removed. A single Gianturco or PDA coil (fig 4) was implanted in five patients, three PDA coils were implanted in one patient, and a single Interlocking Detachable Coil was implanted in one patient. The duct was occluded at angiography in one $(14 \%)$, by the following day in a further three $(43 \%)$, and at six months in two $(28 \%)$ more patients (table 3$)$. In one patient with a PDA coil and a previous Rashkind umbrella procedure the duct was still patent at one year.

\section{Discussion}

A transcatheter approach is now the method of choice for duct occlusion in many paediatric cardiology centres. ${ }^{13}$ The Ivalon plug was the first effective technique but was limited because the large bore arterial sheaths often needed surgical access to the femoral artery. ${ }^{11}$ The Rashkind device, which is usually implanted through the venous route, extended the application to smaller children and infants. ${ }^{12}$ Complete occlusion of the duct by this method was in excess of $80 \%$ for a single device usually within six months of implantation. Though residual leaks close off slowly over the next few years, ${ }^{3}$ many will implant a second device if a leak is present after six to 12 months. ${ }^{4}$ In patients with a very small or tortuous duct, passage of the sheath may be difficult and dilatation of the duct or creation of an arteriovenous guidewire circuit are needed to facilitate passage of the sheath. ${ }^{2}$ The Rashkind umbrella can be front loaded into a smaller sheath, ${ }^{13}$ but in some patients even these techniques fail. The rationale for closure of very small ducts which are often clinically "silent" is debated, ${ }^{14}$ but endocarditis on a silent duct has been reported ${ }^{15}$ and for this reason a simple technique that allows closure of small ducts is useful. For this reason we also pursue complete occlusion in patients with a small leak after Rashkind umbrella implantation.

\section{EXPENSE}

The Rashkind umbrella is expensive (about $£ 1900$ ) and the cost of duct occlusion was similar to that of surgical ligation in a large American series. ${ }^{16}$ Coils are much cheaper (about $£ 32$ for the Gianturco, $£ 150$ for the PDA, and $£ 295$ for the Interlocking Detachable Coil) reducing the procedure costs substantially even if more than one coil is used.

\section{SUCCESS RATE}

Occlusion rates are reported to be as high as $90 \%$ after use of one or more Gianturco coils. ${ }^{89}$ In our experience, on an intention to treat basis, the occlusion rate was $93 \%$ (53/57). When it was possible to implant coils completely within the duct, the success rate was $100 \%$ (9/9) with $56 \%(5 / 9)$ occluded by six weeks and the remainder by one year. When coils were used to straddle the duct the occlusion rate was $86 \%(6 / 7)$ for post umbrella ducts with one duct not occluded at one year, $100 \%(4 / 4)$ for post ligation ducts, and $100 \%$ (34/34) for native ducts.

\section{EMBOLISATION}

In the first cohort the coil embolised in two out of four patients. This reflected both our inexperience in judging the correct size and type of coil and a goal of depositing the entire coil completely inside the duct. Implanting the coil so as to straddle the duct from the pulmonary artery to the aorta has considerably reduced the incidence of embolisation. In this role, the Gianturco coil, when of a sufficient size, is effective in occluding the duct with a low risk of embolisation. The similar PDA coil further reduces the likelihood of embolisation because its screw attachment allows it to be removed or repositioned before release if it is deployed in a suboptimal position. For implantation inside long tubular ducts the Interlocking Detachable Coil has also reduced the incidence of displacement. Though these measures will reduce the incidence of embolisation and the attendant increased fluoroscopy time, sporadic embolisation will still occur and equipment for retrieval and experience in its use is mandatory. ${ }^{7-9}$

\section{ROUTE OF COIL IMPLANTATION}

We and others have implanted the coil through an arterial catheter. ${ }^{79} \mathrm{~A}$ case has been 
made for implantation from the venous side but we do not see any advantage. Aortography is required before, during, and after implantation so that arterial cannulation is required even when the venous approach is used. If coils are deposited entirely within the duct there is no need to cross the narrowest point at the pulmonary end before coil implantation. The use of $4 \mathrm{~F}$ catheters with a 0.038 inch lumen for coil implantation will also reduce the risk of arterial occlusion. Even with the $5 \mathrm{~F}$ catheters we have not had arterial complications.

\section{NUMBER OF COILS}

In one patient in whom a single coil was implanted the coil was removed because of haemolysis. This was early in our experience with larger ducts and we were aware of a significant shunt at the end of the procedure. In a similar situation we would now place as many as four coils at the same procedure. ${ }^{8}$ This applies also to the only patient with a leak one year after coil implantation in whom a significant shunt was present at the end of the procedure. We have not observed any gradients in either the aorta or pulmonary artery after implanting three or four straddling coils.

Our experience suggests that coil implantation is an effective and safe method for duct occlusion when coils of various types are selected according to the duct morphology.

We thank William Cook, Europe for supplying the newly developed PDA coils and Target Therapeutics, USA for supplying their newly developed Interlocking Detachable Coils

1 Anonymous. Transcatheter occlusion of persistent arterial duct. Report of the European Registry. Lancet 1992;340: duct. Rep2-6.
2 Benson LN, Freedom RM. Balloon dilatation of the very small patent ductus arteriosus in preparation for transcatheter occlusion. Cathet Cardiovasc Diagn 1989;18: 48-9.

3 Hosking MC, Benson LN, Musewe N, Dyck JD, Freedom RM. Transcatheter occlusion of the persistently paten ductus arteriosus. Forty-month follow-up and prevalence of residual shunting. Circulation 1991;84:2313-7.

4 Huggon IC, Tabatabaei AH, Qureshi SA, Baker EJ, Tynan $M$. Use of a second transcatheter Rashkind arterial duct occluder for persistent flow after implantation of the firs device: indications and results. Br Heart $\mathcal{f} 1993 ; 69$. 544-50.

5 Ottenkamp J, Hess J, Talsma MD, Buis-Liem TN. Protrusion of the device: a complication of catheter closure of patent ductus arteriosus. Br Heart 7 1992:68: 301-3.

6 Fadley F, al-Halees Z, Galal O, Kumar N, Wilson N. Left pulmonary artery stenosis after transcatheter occlusion of persistent arterial duct [letter]. Lancet 1993;341:559-60.

7 Lloyd TR, Fedderly R, Mendelsohn AM, Sandhu SK Beekman RH III. Transcatheter occlusion of patent ducBeekman RH III. Transcatheter occlusion of patent ductus arterios

8 Hijazi ZM, Geggel RL. Results of anterograde transcatheter closure of patent ductus arteriosus using single or multiple Gianturco coils. Am $\mathcal{F}$ Cardiol 1994;74:925-9.

9 Moore JW, George L, Kirkpatrick SE, Mathewson JW, Spicer RL, Uzark K, et al. Percutaneous closure of the small patent ductus arteriosus using occluding spring coils. $千$ Am Coll Cardiol 1994;23:759-65.

10 Reidy JF, Jones ODH, Tynan M, Baker EJ, Joseph MC Embolisation procedures in congenital heart disease. $B$ Heart $\mathcal{f} 1985 ; 54: 184-92$.

11 Porstmann W, Wierny L. Percutaneous transfemoral closure of the patent ductus arteriosus - an alternative to sure of the patent ductus arteriosus-102.

12 Rursind WJ Mulins CE Hellenbrand WE Tait MA Nonsurgical closure of patent ductus arteriosus: clinical Nonsurgical closure of patent ductus arteriosus: clinical application of the Rashkind

13 Perry SB, Lock JE. Front-loading of double-umbrella devices, a new technique for umbrella delivery for closing cardiovascular defects. Am $\mathcal{f}$ Cardiol 1992;70:917-20.

14 Latson LA. Residual shunts after transcatheter closure of patent ductus arteriosus. A major concern or benign "techno-malady"? Circulation 1991;84:2591-3.

15 Balzer DT, Spray TL, McMullin D, Cottingham W, Canter CE. Endarteritis associated with a clinically silent patent ductus arteriosus. Am Heart f 1993;125:1192-3.

16 Gray DT, Fyler DC, Walker AM, Weinstein MC, Chalmers TC. Clinical outcomes and costs of transcatheter as compared with surgical closure of patent ductus arteriosus. The Patient Ductus Arteriosus Closure Comparative Study Group. $N$ Engl f Med 1993;29: 1517-23. 